\title{
Efeitos discursivos da forma de apresentação dos nomes próprios na referenciação
}

\author{
Lívia Maria Turra Bassetto \\ Fundação Educacional do Município de Assis (FEMA), Assis, São Paulo, Brasil \\ liviamtb@hotmail.com
}

DOI: http://dx.doi.org/10.21165/el.v46i3.1584

\begin{abstract}
Resumo
Este artigo tem o objetivo de demonstrar a importância do emprego de nomes próprios no processo de construção de referentes no texto, em especial como a forma de apresentação desses nomes (nome completo, apenas primeiro nome, apenas sobrenome, apelido, etc.) pode promover efeitos discursivos diferentes e relevantes tanto para a (re)categorização referencial quanto para a construção do sentido no texto. Para isso, este trabalho assume a perspectiva da teoria da Referenciação, da Linguística Textual de linha sócio-cognitivo-interacionista, porém com um olhar diferente sobre o nome próprio, com base em Bassetto (2015), considerando que ele pode assumir, além da função designativa, também a função atributiva, e promover, consequentemente, efeitos discursivos importantes para o texto.
\end{abstract}

Palavras-chave: referenciação; nome próprio; efeitos discursivos.

\section{Discursive effects of the manner of presentation of proper names in referenciation}

\begin{abstract}
This article has the objective of demonstrating the importance of the use of proper names in the process of referential construction in the text, in special how the manner of presentation of these names (full name, only first name, only last name, nickname, etc.) can promote different and relevant discursive effects to the referential (re)categorization and to the construction of meaning on the text. For this purpose, this work assumes the perspective of the Referenciation theory of Textual Linguistics of socio-cognitive-interactionist base line, but with a different view about the proper name, based on Bassetto (2015), considering that it can assume, besides the designative function, also the attributive function, and, consequently, it can promote important discursive effects to the text.
\end{abstract}

Keywords: referenciation; proper name; discursive effects.

\section{Introdução}

O estudo de nomes próprios tem sido realizado há muito tempo a partir de diferentes perspectivas. No entanto, uma concepção que se tem consagrado, principalmente, na tradição gramatical, é a de que o nome próprio exerce papel designativo, ou seja, ele promove a nomeação individual, instituída socialmente, sem apresentar ao ser nomeado nenhuma característica.

A partir desse olhar, o nome próprio tem sido apresentado frequentemente pela gramática tradicional como recurso que nomeia uma pessoa ou um lugar individualmente, enquanto aos nomes comuns fica a função de nomear grupos de "coisas" com características em comum, como destaca Bechara (2004, p. 113): 
SUBSTANTIVO PRÓPRIO é o que se aplica a um objeto ou a um conjunto de objetos, mas sempre individualmente. Isto significa que o substantivo próprio se aplica a esse objeto ou a esse conjunto de objetos, considerando-os como indivíduos. Assim, um nome João, Isabel ou Açores só acidentalmente se aplicará a várias pessoas ou ilhas não porque estas apresentam características comuns que as identificam como membro de uma classe ou conjunto específico. Por isso cada João, cada Isabel e cada Açores é uma pessoa ou ilha considerada inconfundível para as demais. São materialmente idênticos, mas se aplicam a indivíduos diferentes.

Portanto, nessa perspectiva, o nome próprio promove apenas a nomeação individual, ou seja, exerce a função designativa, enquanto o nome comum exerce, além da função designativa - uma vez que nomeia "coisas" -, também a função atributiva.

Em alguns estudos de base funcionalista, como os de Neves (2000), esse olhar sobre o nome próprio se mantém, de modo que, segundo a autora, os nomes comuns são definidos basicamente "pelas funções de denominação e de descrição das classes de referentes" (NEVES, 2000, p. 67, grifos da autora), enquanto:

Os substantivos próprios, diferentemente, não são nomes que se aplicam, em geral, a qualquer elemento de uma classe. Fazendo designação individual dos elementos a que se referem, isto é, identificando um referente único com identidade distinta dos demais referentes, eles não evidenciam traços ou marcas de caracterização de uma classe, e não trazem, pois, uma descrição de seus referentes. (NEVES, 2000, p. 69, grifos da autora).

Por isso, Camacho et al. (2014, p. 35, grifos da autora) afirmam que os nomes próprios "exercem apenas as funções denominadora e referenciadora".

Assim, esse ponto de vista sobre o nome próprio, tão firmado nos estudos linguísticos, acabou por ser incorporado também pelos estudos na área da referenciação, mas os estudos do processo de construção de referentes pouco se voltaram ao uso de nomes próprios e, quando o fizeram, restringiram-se a menções gerais sobre o seu papel na introdução ou na retomada de referentes no texto. Convém ressaltar que, por assumir a concepção de que o nome próprio exerce função designativa apenas, estudiosos da área consideram que ele não é capaz de promover a categorização e a recategorização referencial, como Koch (2008, p. 101-102) destaca:

O primeiro passo na construção de um texto é a introdução de um objeto-de-discurso na memória textual (em geral, por meio de um nome próprio ou forma nominal). [...] Quando a introdução se faz por meio de um nome próprio, tem-se apenas a nomeação do objeto. Já no caso de se tratar de uma expressão nominal, opera-se uma primeira categorização do objeto-de-discurso, o qual, a cada retomada, pode ser mantido como tal ou, então, recategorizado por outras expressões nominais.

Neste trabalho, no entanto, após pesquisas na área da Filosofia da Linguagem, como as de Kleiber (1981, 1994), Jonasson (1994) e de Gary-Prieur (1994, 2001, 2005), observou-se um olhar diferenciado sobre os nomes próprios, analisando o seu funcionamento e apresentando uma divisão entre os "modos de interpretação" do nome próprio, de modo a considerar que o nome próprio possa ser, em determinadas situações de uso, também atributivo.

A partir desses estudos, Bassetto (2015) passou a refletir sobre o papel do nome próprio no processo de construção referencial, organizando o modo de funcionamento 
do nome próprio em um continuum, cujos pontos são (a) nome próprio mais designativo; (b) nome próprio atributivo, com atributo construído no momento da interação verbal; (c) nome próprio atributivo, com atributo mais cristalizado social e culturalmente; e sendo considerado (d) nome comum apenas o epônimo.

Independentemente dos modos de funcionamento do nome próprio, defende-se que este exerce papel importante na construção referencial. No caso do papel designativo, embora a tradição gramatical e alguns estudos da Referenciação indiquem que, no texto, seu efeito seja neutro, este artigo pretende demonstrar como a forma de apresentação do nome próprio (nome completo, apenas primeiro nome, apenas sobrenome, apelido, entre outras formas) é significativa e pode promover efeitos discursivos importantes para a construção referencial.

Convém destacar que, por este artigo ter como base teórica a Linguística Textual, não se faz uma distinção rígida entre "texto" e "discurso", pois, diferentemente da Análise do Discurso, que considera o texto como a materialidade linguística, na perspectiva assumida aqui, o texto vai além da estrutura formal, envolvendo também, no processamento textual, aspectos sociais, culturais e interacionais. Esse olhar sobre o texto pode ser observado na definição de Costa Val (1999, p. 3), que emprega "texto ou discurso", colocando-os como similares: "Pode-se definir texto ou discurso como ocorrência linguística falada ou escrita, de qualquer extensão, dotada de unidade sociocomunicativa, semântica e formal". Para alcançar seu objetivo, este artigo retomará inicialmente conceitos básicos da teoria da Referenciação, apresentará a concepção de nome próprio aqui defendida e, por meio da breve análise realizada, buscará demonstrar os efeitos discursivos que as formas de apresentação do nome próprio podem promover na construção referencial. Por fim, serão apresentadas as considerações finais e as referências consultadas.

\section{Referenciação}

A teoria da Referenciação está inserida na área da Linguística Textual, de linha sócio-cognitivo-interacionista, que considera o texto como lugar de interação entre sujeitos que, por meio da linguagem, (inter)agem, considerando-se os fatores sociais, culturais e cognitivos envolvidos no processo.

Em decorrência desse olhar sobre o texto, a referenciação - como o nome sugere - é uma ação, um processo dinâmico de construção de referentes no discurso. Assim, os sujeitos operam sobre o material linguístico de modo a construir uma versão do mundo, a partir dos seus conhecimentos, do papel assumido por eles e de seus objetivos no momento da interação verbal. Portanto, para o processo de referenciação, a interação é atividade fundamental, uma vez que a construção referencial só pode ser efetivada por meio da negociação de sentido entre os sujeitos no ato de comunicação, ou seja, o sentido do texto não está pronto, mas é construído na interação entre os sujeitos envolvidos - locutor e interlocutor - a partir da ativação de seus conhecimentos, do contexto de produção, entre outros fatores.

A partir desse viés teórico, a construção dos referentes (objetos-de-discurso) dáse pelo autor do texto na relação que este estabelece com o seu interlocutor por meio da linguagem. Logo, a referenciação é um processo intersubjetivo e social, de modo que as (re)elaborações do mundo se dão a partir de condições sociais e culturais. Ou seja, os 
referentes não são construídos objetivamente por todos os sujeitos em qualquer situação comunicativa. Ao contrário, a construção referencial revela pontos-de-vista sobre o mundo e, por isso, os referentes são considerados instáveis, visto que, apesar dos fatores que estabilizam as categorias (cf. MONDADA; DUBOIS, 2003), eles estão em constante transformação, de acordo com os propósitos interacionais ${ }^{1}$ dos interlocutores.

Essa constante transformação do referente no texto decorre de um projeto estratégico do sujeito, que, dentre as possibilidades existentes na língua, faz escolhas lexicais com vistas a um propósito comunicativo e à situação enunciativa, já que, dependendo das situações de interação verbal, um mesmo sujeito pode construir o referente de modo diferente, adequando-se às questões sociais e culturais. Logo, a referenciação é um processo estratégico ${ }^{2}$ e argumentativo, até mesmo porque, na perspectiva da Linguística Textual, a produção textual é:

[...] uma atividade consciente, criativa, que compreende o desenvolvimento de estratégias concretas de ação e a escolha de meios adequados à realização dos objetivos; isto é, trata-se de uma atividade intencional que o falante, de conformidade com as condições sob as quais o texto é produzido, empreende, tentando dar a entender seus propósitos ao destinatário através da manifestação verbal. (KOCH, 2013, p. 26).

As seleções lexicais, por serem argumentativas, são efetuadas tanto para a introdução e retomada referencial, quanto para a caracterização do referente a partir de um olhar. Assim, as estratégias de progressão referencial podem promover a categorização e a recategorização referencial, sendo a categorização a apresentação do referente por meio de uma categoria, que pode se dar, de acordo com os estudos na área da Linguística Textual, por meio das expressões nominais - descrição definida, descrição indefinida, nominalização e associação, sendo as duas primeiras mais frequentes.

Ressalta-se que, entre as estratégias de progressão referencial, não se encontra o nome próprio, mesmo que, em alguns textos, se comente brevemente sobre a possibilidade de se empregar esse recurso para introdução e retomada de referente, como argumentou Koch (2008, op. cit.).

O fato de não se tratar do nome próprio deve-se à visão de que esse recurso não seja capaz de promover a categorização e a recategorização referencial - visão esta diferente da defendida neste artigo -, o que leva a se considerar apenas expressões nominais, cujo núcleo seja um substantivo comum.

Em relação à recategorização, este conceito pode ser visto, em sentido mais estrito, como a transformação do referente por meio da retomada referencial por uma nova categoria. No entanto, têm-se observado, com frequência, olhares mais

\footnotetext{
${ }^{1}$ Embora, para áreas como a Análise do Discurso, o sujeito seja constituído de consciente e inconsciente, para a Linguística Textual, o sujeito é apresentado como consciente, tendo, portanto, um projeto de dizer. No entanto, é preciso ressaltar que o autor, apesar de seus propósitos comunicativos, não tem controle sobre todos os possíveis sentidos que seu texto pode promover, até mesmo porque estes são negociados com seu interlocutor na interação verbal, como já ressaltado anteriormente. Por isso, mesmo que alguns sentidos não tenham sido conscientemente construídos pelo autor, eles podem ser ativados por seu interlocutor.

${ }^{2}$ Convém ressaltar, mais uma vez, que, apesar de se considerar um projeto estratégico do sujeito, este nem sempre tem controle sobre as possibilidades de sentidos a serem construídos no texto, principalmente por eles serem negociados com seus interlocutores no momento da interação verbal.
} 
abrangentes sobre esse processo - embora haja algumas resistências -, considerando-se, além do emprego de expressões renomeadoras, também outros recursos, como o uso da predicação, a associação entre referentes, metáforas, dentre outras possibilidades. A esse respeito, declara Jaguaribe (2004, [n.p.]):

Postulamos, aqui, que as recategorizações possam se dar, no texto literário e no texto não-literário, não só pelo emprego de expressões referenciais, como sugere a literatura sobre o assunto, mas também pelo emprego de expressões atributivas. A recategorização, como processo, não estaria circunscrita aos lindes das expressões referenciais, muito embora se realize bastante por essa estratégia textualizadora. Referido um objeto-do-mundo e transformado esse objeto em objeto-de-discurso, tudo o que se acrescentar sobre ele e o que se suprimir dele, quer seja por um elemento referencial, quer seja por uma expressão atributiva, alterará seu estatuto no discurso, interferirá na maneira como ele será trabalhado cognitivamente pelo interlocutor, devendo ser tratado, portanto, como um processo de recategorização.

Este é o posicionamento assumido neste artigo, embora se destaque que haja pesquisadores que preferem a divisão entre recategorização e processos de repredicação.

A ampliação do conceito de recategorização é também relevante para a finalidade deste artigo - demonstrar o papel das formas de apresentação do nome próprio no processo de referenciação -, visto que se considera o nome próprio não apenas na introdução e progressão do referente, mas também em estruturas textuais variadas, desde que contribuam para a construção referencial. Destaca-se também a importância da inferência para compreender o papel do nome próprio na referenciação, já que nem sempre os atributos do referente e as informações acerca dele estão expressos claramente no texto, mas são subentendidas pelo contexto.

Para demonstrar a importância do nome próprio, inclusive em função designativa, faz-se uma breve discussão acerca da questão do nome próprio.

\section{Nome próprio e suas formas de apresentação no processo de referenciação}

Conforme apresentado anteriormente, a teoria da Referenciação ainda parte do princípio de que o nome próprio, com função basicamente designativa, embora promova a introdução e a progressão referencial, não promove a categorização e recategorização referencial, sendo, por isso, renegado, em muitos casos, pelos trabalhos realizados na área.

Em um de seus textos, Ilari (2005, p. 116) é ainda mais rigoroso com os casos de nomes próprios na referenciação, declarando que:

[...] os nomes próprios só funcionam como anafóricos quando abdicam de sua especificidade de nomes próprios e se tornam comuns. Se esta observação é correta, temos interesse em perguntar que características semânticas de um nome comum o tornam apropriado para a função anafórica. Uma hipótese é que os nomes comuns classificam, ao passo que os nomes próprios apenas designam. Isso poderia estar indicando que, para que haja anáfora, é preciso que haja classificação.

Ou seja, Ilari, além de não considerar o nome próprio como (re)categorizador referencial, não o considera como anafórico, já que não há, segundo ele, classificação. 
No entanto, vale destacar que os pronomes são considerados anafóricos, mesmo sem promover a classificação. Portanto, pode-se notar um olhar bastante rígido sobre o nome próprio.

Neste trabalho, entretanto, apresenta-se um posicionamento bastante diferente, considerando o nome próprio como recurso capaz de promover a introdução e a progressão referencial no texto, mas busca-se principalmente demonstrar como a escolha pelo uso do nome próprio, por ser efetuada pelo interlocutor, tem um propósito comunicativo, mesmo que este seja a busca por uma neutralidade ilusória.

É comum que, principalmente em textos jornalísticos, se mencione a busca pela neutralidade ou imparcialidade. Contudo, sabe-se que, para os estudos textualdiscursivos, não existe discurso neutro. Portanto, mesmo que o autor empregue o nome próprio com o propósito de ser "neutro" em relação ao processo de construção referencial, acredita-se que a forma como esse nome é apresentado revela efeitos discursivos variados no contexto, deixando, portanto, de ser neutro.

Conforme mencionado anteriormente, partindo-se da ideia de continuum $^{3}$, acerca do funcionamento do nome próprio (cf. BASSETTO, 2015), este só passaria à condição de nome comum nos casos de epônimos, visto que o "referente" possuidor daquele nome que gerou o epônimo já não é mais recuperado ou a sua relação já está "desgastada", perdendo-se, assim, a função designativa (como designação individual considerada particular dos nomes próprios). Seriam os casos de "mauricinho", "patricinha", "mecenas", "champagne", entre outros.

Nos casos em que o nome próprio é considerado atributivo - (b) com atributos construídos no momento da interação verbal; ou (c) com atributos mais "consolidados" social e culturalmente -, ele aparece, com mais frequência em predicados (nominais, verbais ou verbo-nominais) ou acompanhado de um modificador que acaba por relacionar dois referentes - o possuidor do nome próprio e o referente a quem este nome é atribuído para a sua recategorização.

Convém salientar que, quando empregados como nomes próprios atributivos seja do tipo (b) ou do (c) -, ainda se recupera o seu papel designativo, o que os manteria como nomes próprios e não como nome comum.

O ponto (a) do continuum, do nome próprio mais designativo, seria aquele que estaria mais próximo da "neutralidade", justamente por ter ressaltada a designação ao invés da atribuição. No entanto, a forma de apresentação do nome próprio é o que, em conjunto com o contexto, promoveria efeitos discursivos relevantes para a referenciação. Buscando demonstrar os efeitos que os nomes próprios podem promover no texto, foram selecionados alguns fragmentos de textos para análise e reflexão.

\section{Análise}

A respeito das formas de apresentação do nome próprio, em função mais designativa, foram selecionados alguns fragmentos que demonstram a importância delas para a construção referencial e para os efeitos discursivos promovidos no texto. Quando

\footnotetext{
${ }^{3}$ Como já apresentado na Introdução deste artigo, o continuum é composto por (a) nome próprio mais designativo; (b) nome próprio atributivo com atributo construído no momento da interação verbal; (c) nome próprio atributivo com atributo mais cristalizado social e culturalmente; e (d) nomes comuns.
} 
se fala em formas de apresentação do nome próprio, considera-se que este pode ser empregado no texto como: nome próprio completo; apenas primeiro nome; apenas sobrenome; apelido, sigla, variações do nome (como diminutivo, aumentativo ou abreviações), uso de inicial minúscula propositalmente, entre outras possibilidades.

Acredita-se que cada uma dessas formas de apresentação seja capaz de promover efeitos discursivos relevantes para o processo de referenciação, de acordo com o contexto de uso. Cabe destacar que esses efeitos são subentendidos no decorrer do texto, nem sempre ficando expressos claramente.

Para demonstrar alguns casos, apresenta-se a seguir um fragmento de uma crônica de Carlos Heitor Cony (2008, grifo nosso):

(01) O jornal tinha vários e brilhantes colunistas, responsáveis por seções fixas, como teatro, cinema, música, artes plásticas, fofocas, livros, rádio e TV, saúde, turismo etc. Eu revezaria com um tal de CDA, este no primeiro caderno, que, além de poeta maior, era cronista dos melhores de todos os tempos. Mais ou menos naquela época, fui convidado a fazer o mesmo na Folha, onde mais uma vez revezava com uma poeta, das maiores de nossa língua: Cecília Meireles. Éramos cronistas - com a óbvia distinção de qualidade. Nem que nascesse mil vezes chegaria ao nível de Drummond e Cecília. Quanto ao tamanho das crônicas, dos seis ou sete parágrafos que o leitor reclama, gosto de citar João Saldanha, que além de fazer "crônicas", tinha uma "coluna" sobre esportes nos vários jornais e emissoras em que atuava. Saldanha dizia que um texto com mais de

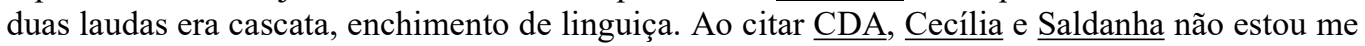
comparando a eles. Faço mal e porcamente o que eles faziam com engenho e arte. $\left(\mathrm{CCM}^{4}\right)$

A introdução do referente "CDA" (Carlos Drummond de Andrade) faz-se por meio da expressão indefinida "um tal de CDA", que poderia suscitar uma provável falta de conhecimento inicial acerca do referente ou mesmo uma ironia por parte do autor, já que se emprega a expressão "um tal de", seguida de uma sigla, que pode não ser diretamente associada ao nome próprio que a forma. Portanto, observa-se que a escolha por essa expressão é proposital.

Na sequência, o referente é pronominalizado por "este" e caracterizado por uma predicação nominal: "além de poeta maior, era cronista dos melhores de todos os tempos". Após a atribuição dessas propriedades ao referente, é possível inferir, com mais facilidade, a sigla em questão, em especial quando o referente é retomado por um de seus sobrenomes, "Drummond". Salienta-se que a opção pelo sobrenome "Drummond" provavelmente se dê devido ao fato de ser um dos nomes mais empregados para a menção ao poeta, de modo que, assim, o autor garanta que o seu interlocutor saiba quem é o referente em construção. Ou seja, nesse contexto, o uso do sobrenome tem a intenção de esclarecer quem é "um tal de CDA", pois, caso fosse empregado "Carlos" ou mesmo "Andrade", a compreensão não seria a mesma, devido ao fato de se empregar comumente "Drummond", no cenário cultural, para fazer referência ao poeta brasileiro.

Outro referente é introduzido no texto pela descrição indefinida "uma poeta", sendo retomado pelos nomes próprios, "Cecília Meireles" (nome próprio completo) e "Cecília" (primeiro nome). Na sequência, introduz-se "João Saldanha" (nome próprio completo), retomado por duas vezes pelo sobrenome "Saldanha".

\footnotetext{
${ }^{4}$ CONY, C. H. Crônicas, colunas e mosquitos. Folha de S. Paulo, São Paulo, 28 de março de 2008, Opinião, p. A2.
} 
Embora esses nomes - "CDA", "Cecília Meireles" e "João Saldanha" - sejam empregados com função designativa, não se pode negar a força argumentativa que eles trazem ao texto, uma vez que eles dão destaque à posição do cronista por ter trabalhado com pessoas consideradas ilustres, não só social e culturalmente, mas também discursivamente. Apesar de o autor ressaltar a diferença entre ele e os demais escritores, o fato de se trabalhar na mesma posição de "Drummond", "Cecília" e "Saldanha" faz com que o cronista reforce a honra desse fato, afinal encontrava-se ao lado não de um escritor qualquer, mas daqueles consagrados na literatura brasileira - no caso de Drummond e Cecília - e no jornalismo, em especial no esportivo, - no caso de Saldanha. Com isso, observa-se que o emprego do nome próprio, nesse caso, é muito mais significativo do que descrições definidas ou indefinidas que pudessem ser usadas.

Ainda a respeito do fragmento acima, destaca-se também a repetição dos nomes próprios no decorrer do texto, o que pode ser entendido como forma de evidenciar os referentes, principalmente pela força argumentativa que os nomes próprios podem proporcionar ao texto. Portanto, mesmo a repetição do nome próprio pode ser um recurso proposital do locutor ao desejar colocar o referente em foco e, assim, ressaltar seu status, visto que é mais comum, social e culturalmente, repetir nomes que sejam discursivamente importantes para aquele contexto. Ou seja, não se pode considerar que o uso dos nomes próprios promova apenas a progressão referencial sem suscitar a relevância que eles assumem no contexto discursivo em questão.

Outro fragmento traz também uma reflexão sobre o uso do nome completo, apenas do primeiro nome e apenas do sobrenome, e seus efeitos para o texto.

(02) Quando convidado para ministro da Cultura, ainda no primeiro governo de Lula, o cantor e compositor Gilberto Gil levantou a premissa: não podia aceitar um cargo que conflitaria com sua vida profissional, que exigiria deslocamentos não compatíveis com uma função que deveria ser exercida em regime de tempo integral. O presidente compreendeu a questão levantada honestamente pelo artista e confirmou o convite, que afinal foi aceito. No segundo governo, Lula manteve o ministro que enfrentava o problema das verbas insuficientes para rodar a máquina oficial destinada a criar e desenvolver atos de cultura. Não deixava de ser uma situação estranha. Um funcionário graduado do governo brasileiro em frequentes turnês artísticas pelo mundo afora. Difícil conciliar as duas funções, sobretudo num ministério sem verbas e incentivo oficial. Na realidade, apesar de seu jogo de cintura pessoal e de sua habilidade política, Gil era criticado pela situação e pela oposição, que cobrava dele uma presença física no organograma da vida pública. Para Gil, foi fácil repetir o acadêmico Eduardo Portella, que ao deixar o Ministério da Educação declarou que não era ministro, mas estava ministro. Lembro um exemplo antigo: ao ser nomeado prefeito de Belo Horizonte, o médico Juscelino Kubitschek avisou ao governador que o nomeara sua intenção de continuar dando expediente no seu consultório e num hospital. Na parte da manhã vestia o avental, clinicava e operava. Na parte da tarde, cuidava da cidade criando metas de trabalho. Não deu para manter o esquema por muito tempo. O volume das obras o exigia, despiu o avental para nunca mais vesti-lo. Sua vocação era a administração. A vocação de Gilberto é outra. ( $\mathrm{SEM}^{5}$, grifo nosso)

Para a introdução referencial, o autor seleciona uma expressão nominal (composta por dois substantivos comuns, acompanhados do nome próprio composto), por meio da qual o autor ressalta duas características relevantes do referente - "cantor e compositor" -, especificando-o por meio do nome "Gilberto Gil". Assim, utiliza-se conjuntamente uma descrição definida e um nome próprio para apresentação do

${ }^{5}$ CONY, C. H. Ser ou estar ministro. Folha de S. Paulo, São Paulo, 03 de agosto de 2008, Opinião, p. A2. 
referente no discurso. Na sequência, a progressão referencial se dá pelo emprego de, respectivamente, duas descrições definidas - "o artista" e "o ministro que enfrentava o problema das verbas insuficientes para rodar a máquina oficial destinada a criar e desenvolver atos de cultura" -, por uma descrição indefinida - "um funcionário graduado do governo brasileiro em frequentes turnês artísticas pelo mundo afora" -, pelo nome próprio - "Gil" -, pela pronominalização - "ele" - e pelos nomes próprios "Gil" e "Gilberto".

A introdução por meio do nome completo permite que o interlocutor identifique mais facilmente quem é o referente em construção, principalmente porque este é uma versão interpretada e reelaborada da figura pública conhecida socialmente, Gilberto Gil. Para a retomada do referente, opta-se ora pelo primeiro nome, ora pelo sobrenome. Embora o uso de "Gil" e de "Gilberto" possa ser aleatório - visto que não se tem como ter acesso ao projeto de dizer do autor -, pode-se pensar que a seleção de um ou outro tenha o objetivo de destacar diferentes "manifestações" do mesmo referente. Ou seja, emprega-se o sobrenome "Gil" - que pode suscitar maior formalidade - ao tratar do referente na função de ministro, considerada mais formal. Já "Gilberto", o primeiro nome, pela familiaridade que geralmente suscita, mesmo não sempre empregado comumente para fazer menção ao artista em questão, pode ter sido selecionado para ressaltar a popularidade proporcionada pela condição de artista, indicada na oposição artista X ministro, proposta pelo autor em seu texto. Assim, pode-se notar a importância das operações realizadas sobre o nome próprio na construção referencial, já que o locutor pode selecionar a forma de apresentação do nome próprio mais adequada ao contexto e aos seus propósitos comunicativos.

Já, no fragmento abaixo, encontra-se o emprego de uma variação convencional socialmente do nome próprio "Francisco", utilizado como "Chico".

(03) Dom Milton Santos de Figueiredo, arcebispo de Cuiabá, ao G1: "Temos um Chico como Papa, o que não era o esperado. O Espírito Santo deu um baile em todas as previsões”. (VRP ${ }^{7}$, grifo nosso)

A expressão em destaque, "um Chico", é bastante significativa na introdução e construção do referente "Papa", nesse contexto. Por meio dessa forma abreviada e popular do nome "Francisco", antecedida pelo artigo indefinido, tem-se reforçado o caráter humilde, popular, de voto de pobreza e de respeito ao próximo, tão exaltados na figura de Francisco de Assis - que havia motivado a escolha do Papa pelo nome de "Francisco" -, e atribuídos ao novo Papa. Pode-se observar maior força argumentativa presente em "um Chico", em comparação a "um Francisco", por exemplo, já que "Chico" é considerado, social e culturalmente, nome/apelido popular no Brasil.

Em um exemplo bastante informal, retirado de uma postagem de Facebook realizada por Marcos Bagno, em 02 de abril de 2016, observa-se como, propositalmente,

\footnotetext{
${ }^{6}$ Embora "Gil", em muitos casos, possa soar mais afetuoso do que propriamente "Gilberto", além de ser também muito mais comum na alusão à figura pública de Gilberto Gil, na oposição primeiro nome $X$ sobrenome, sustenta-se a ideia de que o primeiro nome, mesmo o seu uso sendo pouco comum em determinados contextos, evidencia maior familiaridade do que o emprego do sobrenome, que evidencia maior formalidade.

${ }^{7}$ Fragmento retirado do texto "Veja repercussão do anúncio do novo Papa Francisco". Disponível em: $<$ http://g1.globo.com/mundo/renuncia-sucessao-papa-bento-xvi/noticia/2013/03/veja-repercussao-doanuncio-do-novo-papa-o-cardeal-jorge-mario-bergoglio.html>. Acesso em: 26 mar. 2016.
} 
o uso da inicial minúscula em um nome próprio revela um olhar acerca do referente em construção.

(04) Tenho muitxs amigx estrangeirxs que não acreditam que revistas como veja e istoé não sejam versões brasileiras de Mad e de outras publicações cômicas e satíricas. De fato, qualquer pessoa sensata duvida da seriedade desse jornalixo. Mas, por outro lado, qualquer pessoa que conheça um mínimo da história da nossa direita escravocrata fascista torturadora genocida entende perfeitamente bem o que se passa no cérebro entorpecido dessa gente que não tem o mínimo senso de humanidade. (grifos nosso)

Em comentário a respeito da revista Veja e Istoé, Bagno prefere empregar os nomes das revistas com inicial minúscula para demonstrar a falta de importância desses veículos de comunicação, em sua opinião. Isso pode ser confirmado por meio da comparação com o uso de maiúscula ao mencionar a revista Mad, revista norteamericana de humor satírico, o que sugeriria que esta seja realmente uma revista, enquanto as outras duas sejam desvalorizadas, a ponto de serem recategorizadas pela descrição definida "esse jornalixo" - substantivo formado a partir da junção de "jornalismo" e "lixo", que reforça ainda mais a desvalorização das revistas, visto que lixo é um material sem valor e sem utilidade, por isso, podendo ser descartado.

Assim, por meio dos fragmentos selecionados e analisados, buscou-se demonstrar a importância da escolha pelo modo de apresentação do nome próprio no texto, visto que, de acordo com a situação comunicativa, cada modo de apresentação pode revelar efeitos discursivos variados.

\section{Considerações finais}

Com este artigo, pretendeu-se suscitar algumas reflexões sobre a função do nome próprio na referenciação, em especial, como a sua forma de apresentação pode revelar propósitos comunicativos diversos e efeitos discursivos relevantes para a construção do referente e do texto.

Ampliando-se, portanto, a visão acerca do nome próprio, neste trabalho, não se considera que esse recurso linguístico seja discursivamente neutro, até porque, na perspectiva da Linguística Textual, não se considera que haja discurso neutro. Assim, o sujeito, ao operar sobre o material linguístico, faz opções entre as possibilidades linguísticas para a construção dos referentes no texto, com base em seus propósitos comunicativos, sendo estes alcançados ou não. Portanto, essa escolha é realizada a partir de um ponto de vista, que pode motivar a opção pelo uso do nome próprio e suas formas de apresentação.

Desse modo, acredita-se que as formas de apresentação do nome próprio possam revelar (in)formalidade, intimidade, afeto, (des)valorização do referente, entre outros efeitos, de acordo com o contexto de uso.

\section{REFERÊNCIAS}

BASSETTO, L. M. T. O funcionamento de nomes próprios no processo de referenciação. 2015. 202 f. Tese (Doutorado em Estudos Linguísticos) - Instituto de Biociências, Letras e Ciências Exatas, Universidade Estadual Paulista, 2015. 
BECHARA, E. Moderna gramática portuguesa. 37. ed. rev. e ampl. 14. reimp. Rio de Janeiro: Lucerna, 2004.

CAMACHO, R. G. et al. O substantivo. In: ILARI, R. (Org.). Gramática do português culto falado no Brasil: volume III: palavras de classe aberta. São Paulo: Contexto, 2014. p. 13-63.

COSTA VAL, M. da G. Redação e Textualidade. São Paulo: Martins Fontes: 1999.

GARY-PRIEUR, M. N. Grammaire du nom propre. Paris: Presses Universitaires de France, 1994.

L'individu pluriel: les noms propres et le nombre. In: Sciences $d u$ Langage. Paris: CNRS, 2001.

Où il est montré que le nom propre n'est (presque) jamais "modifié". Langue Française - noms propres: la modification, Paris: Larousse, n. 146, p. 53-66, 2005.

ILARI, R. Alguns problemas no estudo da anáfora textual. In: KOCH, I. G. V.; MORATO, E. M.; BENTES, A. C. (Org.). Referenciação e discurso. São Paulo: Contexto, 2005. p. 103-124.

JAGUARIBE, V. M. F. O jogo da recategorização no texto poético. In: CAVALCANTE, M. M.; BRITO, M. A. P. (Org.). Gêneros textuais e referenciação. Fortaleza: Protexto - UFC, 2004. CD-Rom.

JONASSON, K. Le nom propre: constructions et interprétations. Lourain-la- Neuve: Duculot, 1994.

KLEIBER, G. Nominales. Essais de sémantique référentielle. Paris: Armand Colin, 1994.

Problèmes de référence: descriptions définies et noms propres. Paris: Klincksieck, 1981.

KOCH, I. G. V. Como se constroem e reconstroem objetos-de-discurso. In: Revista Investigações, v. 21, n. 2, p. 99-114, 2008. Disponível em: $<$ http://www.repositorios.ufpe.br/revistas/index.php/INV/article/view/1446/1123>. Acesso em: 05 ago. 2016. O texto e a construção dos sentidos. 10. ed. São Paulo: Contexto, 2013.

MONDADA, L.; DUBOIS, D. Construção dos objetos de discurso e categorização: uma abordagem dos processos de referenciação. In: CAVALCANTE, M. M. et al. Referenciação. São Paulo: Contexto, 2003.

NEVES, M. H. de M. Gramática de usos do português. São Paulo: Editora UNESP, 2000 .

Recebido em: 16/08/2016

Aprovado em: 17/02/2017 